\title{
PL-4 (CIP596131.4): an Improved Potato Haploid Inducer
}

\author{
Benny Ordoñez ${ }^{1,2,3}$ (D) Monica Santayana ${ }^{2} \cdot$ Mariela Aponte $^{2} \cdot$ Isabelle M. Henry $^{1} \cdot$ Luca Comai $^{1} \cdot$ Raúl Eyzaguirre $^{2}$. \\ Hannele Lindqvist-Kreuze ${ }^{2} \cdot$ Merideth Bonierbale $^{2,4}$
}

Accepted: 11 June 2021 / Published online: 12 July 2021

(C) The Author(s) 2021

\begin{abstract}
Dihaploid production from elite tetraploid cultivars is key to both traditional and novel breeding approaches that seek to simplify potato genetics. For this purpose, efficient and widely compatible haploid inducers (HIs) are needed. We compared PL-4, a new HI developed at the International Potato Center, to known HIs IvP101 and IvP35. By pollination of elite tetraploid breeding lines, we showed that PL-4 performed significantly better and had a homogeneous response regardless of the genetic background of the pistillate parents, on the most important efficiency traits-number of dihaploids per 100 fruits and haploid induction rate. Moreover, PL-4 exhibited a reduced proportion of hybrid seeds, a convenient trait for efficient screening. In this context, we recommend PL-4 as an enhanced HI for the potato breeding community.
\end{abstract}

\section{Resumen}

La producción de dihaploides a partir de cultivares tetraploides élite es clave tanto para los enfoques tradicionales como novedosos que buscan simplificar la genética de la papa. Para este propósito, se necesitan inductores haploides (HIs) eficientes y de amplia compatibilidad. Comparamos PL-4, un HI nuevo desarrollado en el Centro Internacional de la Papa, con los conocidos IvP101 e IvP35. Mediante la polinización de un conjunto de líneas tetraploides élite, demostramos que PL-4 se desempeñó significativamente mejor y mostró una respuesta homogénea, independientemente del fondo genético de los padres pistilados, en los rasgos eficientes más importantes: número de dihaploides por 100 frutos y tasa de inducción de dihaploides. Además, PL-4 exhibió una cantidad reducida de semilla híbrida, un rasgo conveniente para un tamizaje rápido. En este contexto, recomendamos PL-4 como un HI mejorado para la comunidad de mejoramiento de la papa.

Keywords Dihaploids $\cdot$ Haploid induction rate $(\mathrm{HIR}) \cdot$ Solanum $\cdot$ Cytoplasm type

\section{Introduction}

The cultivated potato, Solanum tuberosum L. $(2 \mathrm{n}=4 \mathrm{x}=48)$, is a tetraploid crop with polysomic inheritance, and high levels of heterozygosity (Bradshaw 2007). Its polyploid nature complicates genetic studies and can limit genetic gains in breeding. To overcome these problematic aspects, a new breeding

Benny Ordoñez

bordonez@ucdavis.edu

1 Plant Biology and Genome Center, University of California, 1 Shields Avenue, Davis, CA 95616, USA

2 International Potato Center (CIP), P.O. Box 1558, 12 Lima, Peru

3 Integrative Genetics and Genomics Graduate Group, University of California, Davis, CA 95616, USA

4 Present address: Duquesa Business Centre, P.O. Box 157, 29692 Manilva, Malaga, Spain strategy has been proposed that reinvents potato as a diploid inbred-line based system (Jansky et al. 2016). Breeding at the diploid level involves the reduction of ploidy level via the generation of haploid or "dihaploid" $(2 n=2 x=24)$ plants from tetraploid varieties or stocks. The hypothetical benefits include a shorter breeding cycle, faster stacking of traits of interest, and more prolific seed production. This could allow for easier variety generation. A large-scale dihaploid generation is a crucial step of this new potato breeding strategy (Lindhout et al. 2011).

Two methods are used to produce potato dihaploids: anther culture (Rokka et al. 1996) and in vivo haploid induction using specific diploid accessions from the Phureja Group of S. tuberosum as pollinators (hereafter called 'haploid inducers'). Clones phu 1.22 (PI225682), IvP35, IvP48, and IvP101 are haploid inducers (HIs) commonly used in breeding (Peloquin et al. 1996; Hutten et al. 1993; Van Breukelen et al. 1977). These HIs are homozygous dominant for anthocyanin pigments that are visible as an embryo spot on the botanical 
seed and as nodal bands on the stem of young plants (Hermsen and Verdenius 1973). The presence of this pigmentation marker allows discernment between hybrids and putative dihaploids, starting at the seed stage. Unpigmented embryos or seedlings are the desired dihaploids.

Three hypotheses have been proposed for the mechanism of haploid induction in potatoes: parthenogenesis, parentspecific chromosome elimination and egg-pseudo fertilization (Wangenheim et al. 1960; Clulow et al. 1991; Amundson et al. 2021). The exact mechanism at play has not yet been elucidated.

Haploid induction appears to be a monophyletic trait in potatoes. All documented HI derive from the same diploid taxon/germplasm source, but their efficiency differs among them (Hutten et al. 1993). Potato breeders have been attempting to generate new and better HIs. For example, Ortiz et al. (1993) self-pollinated IvP35 and obtained a clone that reached fivefold the rate of spotless seeds to total seeds of IvP35. Later, CIP breeders crossed IvP35 and IvP101 and identified in the resulting progeny a new HI called PL-4 (CIP596131.4, also known as C96HI-01.4). Their data suggested that PL-4 exhibited a higher haploid induction rate $(H I R)$ than both parents, but the supporting experiments employed variable recording methods that lacked replication and complete ploidy analysis (Ortiz and Mihovilovich 2020). To assess the efficiency of PL-4 as a HI, we evaluated and compared the most important haploid induction traits, under a uniform experimental framework and using a novel mixed model for statistical analysis. We also analyzed the effect of parentals' cytoplasm type due to their relationship with male sterility and the urgent need to incorporate different cytoplasmic types into breeding schemes.

\section{Materials and Methods}

\section{PL-4 Reproductive Biology and Pollen Viability}

PL-4 reproductive biology was assessed using descriptors based on (Gomez 2006) and the Crop Ontology Curation Tool (https://www.cropontology.org/, 2011).

HIs plants grown under standard conditions in the screenhouse (see below) were used for pollen fertility evaluation. Pollen viability and frequency of $2 \mathrm{n}$ pollen were determined as described previously by Ordoñez et al. (2017).

\section{Haploid Induction}

Forty CIP elite $4 \mathrm{x}$ breeding lines with different genetic backgrounds and desirable attributes (Supplemental Table 1), were used as pistillate parents in crosses with three HIs, PL-4, IvP101 and IvP35.
Haploid induction crosses were performed during 2015, 2016, and 2017 in screenhouses (average temperature: $19.5^{\circ} \mathrm{C}$ day and $11.6^{\circ} \mathrm{C}$ night; relative humidity range: 56.8-87.4\%) located at the CIP's experimental station in the Peruvian Andes (3216 masl, $-12.01039,-75.22411)$.

Flower buds of the pistillate parents were emasculated, and then pollinated with HI pollen the next day. Each HI was assigned to a separate set of pistillate plants to avoid pollination of the same plant with different HIs.

Fruits were harvested forty-eight days after pollination and the seeds were extracted from mature fruits only. The seed progeny was categorized into two different types: welldeveloped (spotted and spotless) and shrivelled seeds. Only well-developed seeds were recorded in this study. Seeds displaying the $\mathrm{HI}$ embryo spot trait were then discarded, while spotless seeds (i.e., putative dihaploids) were treated with 1500 ppm gibberellic acid (GA3) for one day to break dormancy and incubated on a damp filter paper at $17^{\circ} \mathrm{C}$ for five days. After emergence, seedlings showing nodal anthocyanin bands were removed. The remaining seedlings were transplanted into Jiffy's strips (Jiffystrips ${ }^{\circledR}$ ) and grown in the screenhouse for further evaluations.

\section{Ploidy Assessment}

Ploidy was assessed first by counting chloroplast number in stomata guard cells as described by Ordoñez et al. (2017). In those cases where the average chloroplast count was greater than eight, individuals were assigned as non-conclusive status and ploidy was estimated by flow cytometry. Flow cytometry was performed as previously described by Amundson et al. (2020). Plantlets showing a reduced growth rate that could not be evaluated by chloroplast counting were also included in the flow cytometry assessment.

A schematic diagram of the workflow of this study is shown in Fig. 1.

\section{Data Analysis}

Two 'productivity' and five 'efficiency' traits were estimated to evaluate the performance of the HIs. The productivity traits were: Fruit set percentage (FSP), which is the number of fruits per 100 pollinated flowers and seed set rate $(S S)$, which is calculated by dividing the number of well-developed seeds by the number of fruits.

For the purpose of documenting and analyzing the efficiency of haploid induction, the total number of spotted seeds per 100 fruits was referred to as Spotted100F; the total number of spotless seeds per 100 fruits was referred to as Spotless $100 F$; the total number of dihaploids per 100 pollinations was referred to as $D H 100 P$; and the total number of dihaploids per 100 fruits was referred to as $D H 100 F$. Haploid induction rate 


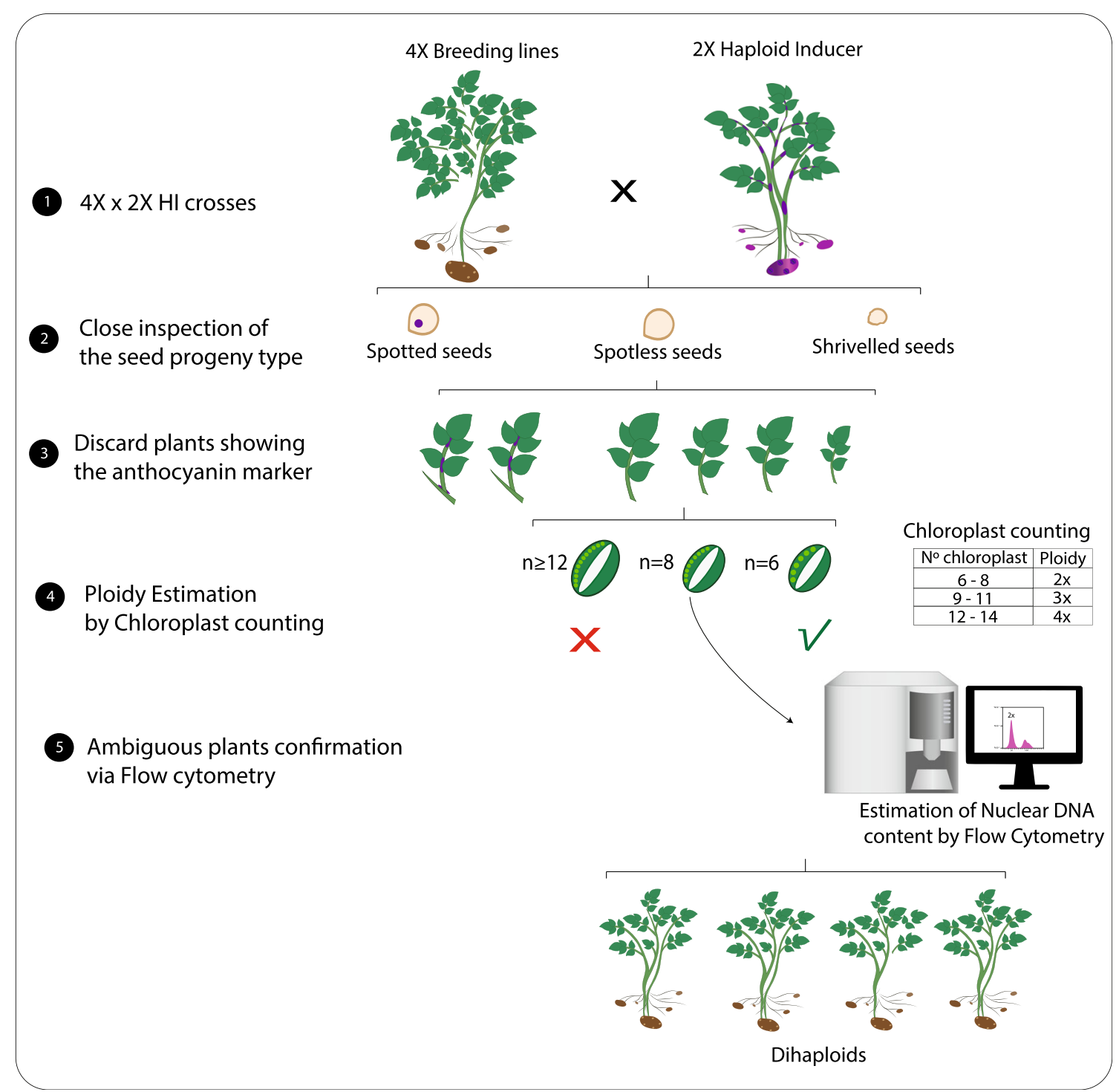

Fig. 1 Workflow for identifying dihaploids as a multi-step process. Observation of the anthocyanin marker in embryos and stems, followed by chloroplast counts allowed the rapid discarding of tetraploid or triploid

$(H I R)$ was defined as the percentage of dihaploids found in the total number of well-developed seeds generated.

Descriptive statistics showed that variance values for productivity and efficiency traits were different among HIs. Therefore, a heterogeneous variance model was considered. To evaluate the general performance of the HIs, a linear mixed model where HIs are fixed effects and pistillate parents are random effects was used. In addition, to examine the effect of the cytoplasm type of the pistillate parent on the efficiency traits (i.e., $D H 100 P, D H 100 F$ and $H I R$ ), a model was adjusted for each $\mathrm{HI}$ where the cytoplasm types were considered fixed effects.

The ASReml-R (Butler et al. 2017) and the asremlPlus (Brien 2020) packages for $\mathrm{R}$ software 4.0.4 (R Core Team 2020) were used to estimate the models and to perform pairwise comparisons. Significance for the fixed effects was hybrids from the putative dihaploids in early development stages. Ambiguous plants were confirmed by flow cytometry

assessed using Wald test. Pearson's correlation coefficients were determined to measure the linear association between the characters obtained by the different HIs.

Raw datasets are available on Dataverse at https://data. cipotato.org/dataset. $x$ tml?persistentId=doi:10.21223/ SP9MFB

\section{Results}

\section{PL-4 Reproductive Biology and Pollen Viability}

Photographs of representative parts of PL-4 are shown in Fig. 2. PL-4 exhibited a moderate flowering degree. The average number of inflorescences per plant was 4 (range 2-5) with 5 flowers (range 3-10) per inflorescence. Pollen 

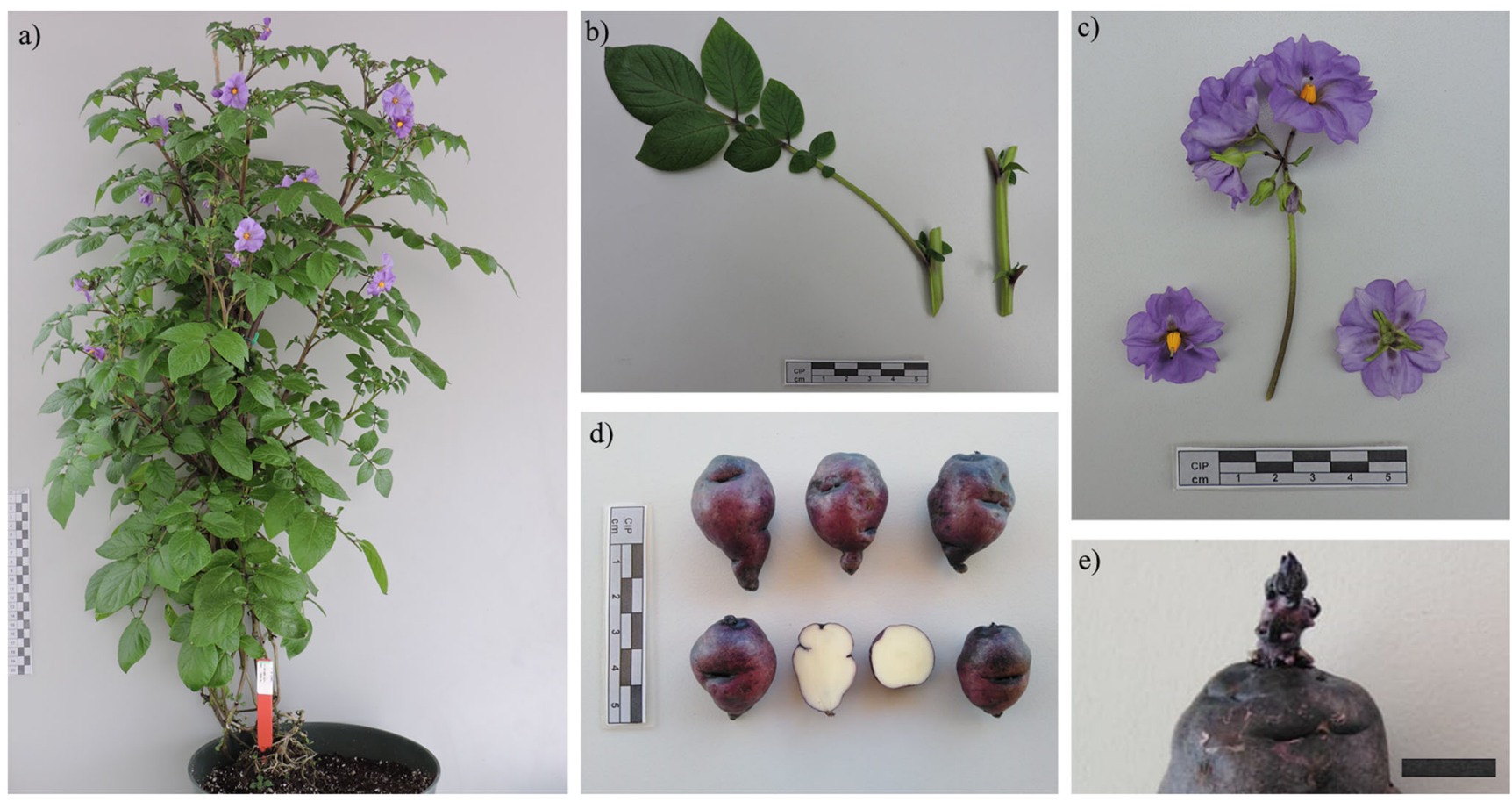

Fig. 2 Representative photographs of PL-4. (a) Whole plant at the flowering stage. PL-4 displayed a semi-erect growth habit. (b) Adaxial side of leaf. Stems were purple with extended green pigments on the surface and intense dark purple nodal bands. (c) Inflorescence and flowers. Flowers had a rotated form. The stigma shape was capitate with

production was moderate ( 3 on a $0-5$ scale with 0 being none and 5 abundant), but greater than IvP35 and IvP101. Under our screenhouse conditions, the three HIs displayed moderate pollen viability (range: $65-80 \%$, Ordoñez et al. 2017). As for $2 \mathrm{n}$ pollen production, PL-4 showed a low percentage of $2 \mathrm{n}$ pollen, whereas both IvP101 and IvP35 showed no presence of $2 n$ pollen.

\section{Haploid Induction}

A total of 9705 pollinations were performed between the CIP elite $4 \mathrm{x}$ breeding lines and the HIs-IvP35, IvP101 and PL-4, setting a total of 2375 fruits, 21,356 seeds and 1612 dihaploids over the span of three years. The number of flowers pollinated a purple color. Anthers had a yellow-orange color. (d) Tubers. The tuber shape was obovate and had slightly deep eyes. Tuber skin was predominantly purplish-red with dark purple spots. The tuber flesh color was cream and there was no secondary flesh color., and (e) Sprout. Mainly apical sprouts of predominantly purple color. Gray bar indicates $1 \mathrm{~cm}$ per HI was in the range of 17-451 for PL-4 (mean = 102), 16587 for IvP101 $($ mean $=139)$ and 16-434 for IvP35 $($ mean $=$ 123). The number of fruits per $\mathrm{HI}$ ranged from 0 to 120 in PL4 , from 0 to 103 in IvP101 and from 2 to 185 in IvP35. We found no significant differences in FSP among the HIs. In contrast, IvP35 displayed a higher SS than IvP101 and PL-4 (Table 1). Shrivelled seeds were also observed in all the crosses, but it was not feasible to record their number.

Over the course of the three years of experimentation, PL-4 generated a total of 813 dihaploids, while IvP101 and IvP35 had 272 and 527, respectively. PL-4 yielded 193.9 Spotless $100 F$ while IvP101 and IvP35 yielded 140.3 and 147.7 , respectively. These results suggest no significant differences between the HIs for this variable. Interestingly, IvP35
Table 1 Pooled data per HI on seven haploid induction traits. Data is averaged across three years (2015-2017)

\begin{tabular}{lllll}
\hline Characters & Abbreviation & PL-4 & IvP101 & IvP35 \\
\hline Fruit set percentage (\%) & FSP & $30.0 \mathrm{a}$ & $26.8 \mathrm{a}$ & $34.0 \mathrm{a}$ \\
Seed set rate & SS & $6.73 \mathrm{~b}$ & $7.31 \mathrm{ab}$ & $9.67 \mathrm{a}$ \\
Spotted seeds per 100 fruits & Spotted100F & $476.9 \mathrm{~b}$ & $579.9 \mathrm{~b}$ & $820.7 \mathrm{a}$ \\
Spotless seeds per 100 fruits & Spotless 100F & $193.9 \mathrm{a}$ & $140.3 \mathrm{a}$ & $147.7 \mathrm{a}$ \\
Dihaploids per 100 pollinations & DH100P & $21.2 \mathrm{a}$ & $13.2 \mathrm{ab}$ & $12.0 \mathrm{~b}$ \\
Dihaploids per 100 fruits & DH100F & $69.8 \mathrm{a}$ & $44.0 \mathrm{~b}$ & $39.4 \mathrm{~b}$ \\
Haploid Induction Rate (\%) & HIR & $11.6 \mathrm{a}$ & $6.8 \mathrm{~b}$ & $4.3 \mathrm{~b}$ \\
\hline
\end{tabular}

Values followed by the same lowercase letter are not significantly different at $p<0.05$ 
yielded the most Spotted $100 F$, at 820.7 compared to PL-4 and IvP101 with 476.9 and 579.9, respectively. PL-4 produced significantly fewer spotted seeds and exhibited higher Spotless $100 F$ values. Additionally, PL-4 produced more $D H 100 P$ than either IvP101 or IvP35. PL-4 produced the most $D H 100 F(69.8)$ while, both IvP101 and IvP35 produced fewer (44 and 39.4, respectively). Overall, PL-4 displayed a higher HIR (11.6\%) compared to IvP101 and IvP35 (6.8\% and 4.3\%, respectively, Table 1).

After sowing the spotless seeds, some developing seedlings were found to be false positive, i.e., not dihaploids, upon chloroplast counting and flow cytometry. On average $4.8 \%$ of the total plantlets from each $\mathrm{HI}$ displayed the anthocyanin marker in stems and were therefore discarded. From the remaining plantlets, confirmed dihaploids were $78.1 \%, 68.0 \%$ and $57.9 \%$ for PL-4, IvP101 and IvP35, respectively. The rest of the plantlets were triploids or tetraploids.

PL-4 showed a high positive correlation between Spotless $100 F$ and DH100F $(\mathrm{r}=0.91, p<0.001)$ whereas that relationship was not as robust for IvP101 $(\mathrm{r}=0.61, p<0.01)$ or IvP35 $(\mathrm{r}=0.64, p<0.001)$. In contrast, $S S$ and Spotless $100 F$ were moderately correlated for PL-4 $(\mathrm{r}=0.61$, $p<0.001)$ and IvP101 $(\mathrm{r}=0.60, p<0.01)$. Notably, IvP101, but neither IvP35 nor PL-4, displayed a significant correlation between FSP and DH100P ( $\mathrm{r}=0.81, p<0.001)$.

Dead and abnormal seedlings of undetermined ploidy occurred in the HI cross progeny (6.7\% for PL-4, 2.3\% and 5.6\% for IvP101 and IvP35, respectively). Abnormal dihaploids were also noted (1.4\% for PL-4, $10.1 \%$ and $6.3 \%$ for IvP101 and IvP35, respectively). These could represent extreme aneuploidy cases (Tan et al. 2015; Amundson et al. 2021).

The values for efficiency traits varied among the pistillate parents as well as the HIs. Of the 40 pistillate parents used in this study, 10 showed DH100F higher than 69.4, which was PL-4 average. These pistillate parents were: CIP392820.1, CIP300056.33, CIP313051.7, CIP390637.1, CIP391180.6, CIP397077.16, CIP398208.219, CIP388615.22, CIP388676.1 and CIP300093.14. The pistillate parent CIP392820.1 yielded the highest DH100F (282) followed by CIP300056.33 with 220. In contrast, CIP313050.21 and Serranita, a popular Peruvian variety, did not produce any dihaploid with any HI (Supplemental Table 2).

\section{Performance of Hls across the Cytoplasm Types}

The cytoplasm type of the pistillate parent is correlated with the incidence of male sterility in their descendants, an important trait for breeding (Hosaka and Sanetomo 2012; Provan et al. 1999). Therefore, we examined the influence of cytoplasm of the pistillate parents on the efficiency traits i.e., $H I R$, DH100F and DH100P.

Pistillate parents were grouped by their cytoplasm types, which were previously determined by Mihovilovich et al.
(2015) using the method and nomenclature by Hosaka and Sanetomo (2012): 19 had the D-type cytoplasm, 13 had the T-type, 7 had the $\mathrm{W}$-type and 1 had the A-type. For the analysis, only dihaploids belonging to the T $(n=738), \mathrm{W}(n=$ $469)$ and $\mathrm{D}(n=402)$ cytoplasm were considered as observations.

Pistillate parents with W-type cytoplasm showed higher $H I R$ and $D H 100 F$ for each HI, followed by parents with Ttype and D- type. Pistillate parents harboring D-type cytoplasm, which is usually associated with male sterility, displayed the lowest values for the following traits: FSP, Spotless100F, DH100P, DH100F and HIR (Data not shown). Nonetheless, we found that PL-4 displayed a more homogeneous response across the different cytoplasm types for the efficiency traits - HIR $(p$ value $=0.870)$ and DH100F $(p$ value $=0.335)($ Fig. $3 \mathrm{a}$ and $3 \mathrm{~b}$, respectively $)$.

\section{Discussion}

A HI that yields more dihaploids regardless of the pistillate parent, would greatly benefit potato breeding by reducing dihaploid production costs and speeding-up the development of diploid parental lines. Nevertheless, since the release of the IvPs (Hermsen and Verdenius 1973), no new HI has become available. Here, we describe a new HI, PL-4, which displays desirable features. PL-4 has been used for multiple years by CIP breeders. For example, during production of a dihaploid mapping population for PLRV resistance from the tetraploid landrace LOP-868, Velásquez (2005) observed that PL-4 generated a higher number of dihaploids than IvP101. Subsequently, Mihovilovich et al. (2013) only used PL-4, finding a HIR of $16.7 \%$, which is higher than that expected from IvP101.

Although the CIP clones used for this study are different from the typical North American and European clones, they nonetheless represent a broad genetic range of potato variation and provide an interesting test of haploid induction efficiency. Our findings provide evidence for PL-4's high HIR and broad pistillate parent compatibility.

Consistent production and pollen fertility are the first requirements for dihaploid production. In addition to profuse flowering and pollen shedding capacity, in our study the three HIs displayed a moderate pollen viability. Environmental conditions may affect viability as Dongyu et al. (1995) observed high and low pollen viability rates in IvP35 and IvP101 across environments, respectively. Previously, Liu and Douches (1993) chose not to work with IvP35 due to poor pollen production. Taken together, our observations suggest that PL-4 carries favorable reproductive traits compared to the IvPs.

The availability of dihaploid identification systems is critical for efficient dihaploid production. Visual differentiation is based on the dominant anthocyanin marker observed in seed 
Fig. 3 Performance of the three HIs considering cytoplasm type as a factor. (a) Haploid Induction Rate $(H I R)$. (b) Dihaploids per 100 fruits $(D H 100 F)$. $p$-values of Wald test are shown below each bar group

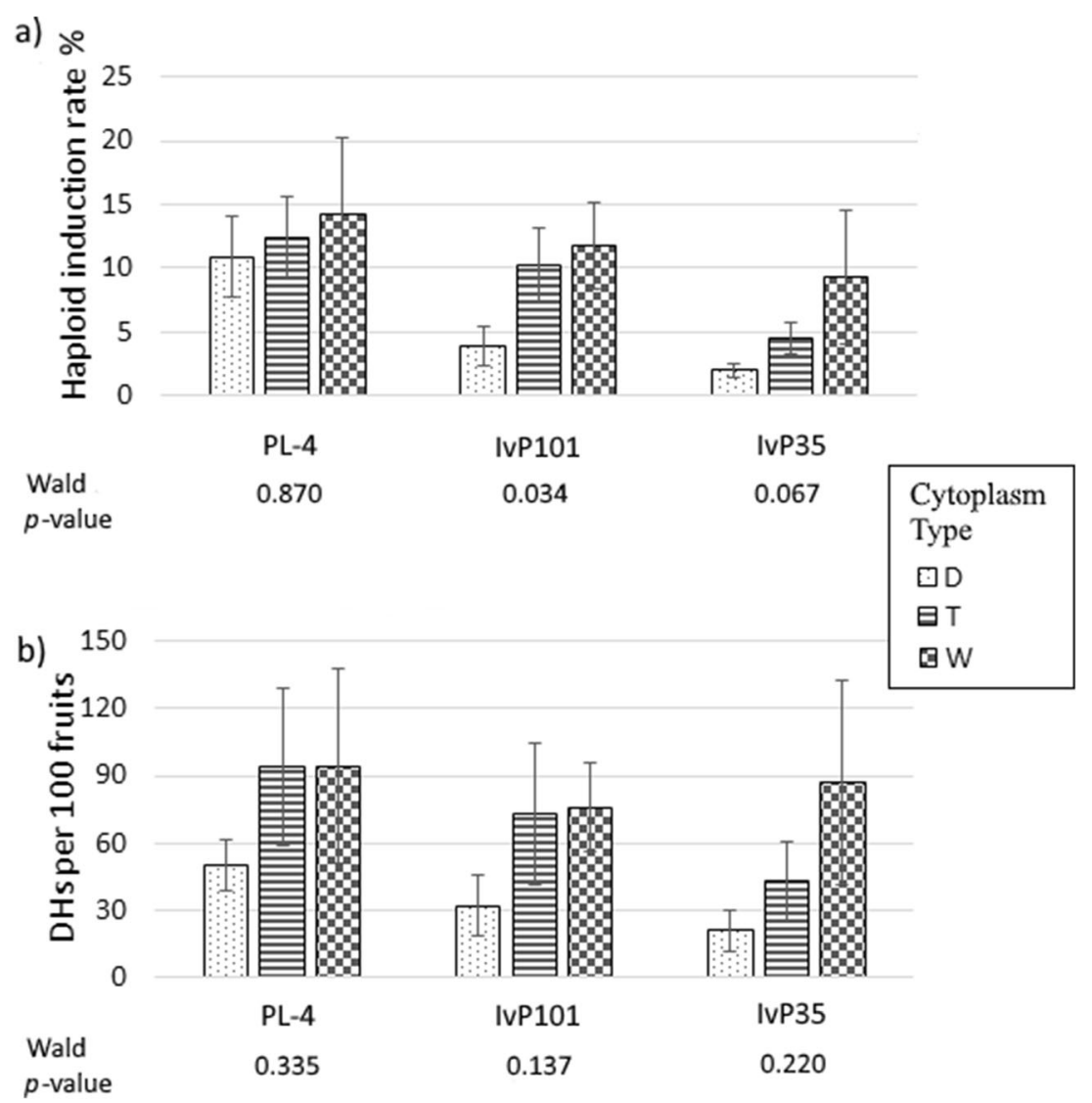

and stems (Hermsen and Verdenius 1973). By using both the seed spot and the nodal band on seedling, we observed a false positive rate of $21.9 \%$ in PL-4 compared to $32.0 \%$ and $42.1 \%$ for IvP101 and IvP35, respectively. These results indicate that potato HIs need a better dihaploid identification approach as suggested by Liu and Douches (1993). Despite the moderate rates of false positives, our study suggests that PL-4 can be useful in a large-scale dihaploid production scheme.

Our study is one of the very few that investigates the potential of new HIs. Often, these studies on haploid induction only used limited numbers of pistillate parents. Nonetheless, the traits evaluated here were consistent across multiple studies. For example, DH100F values for $p h u 1.22$ were 13.9 (Montelongo-Escobedo and Rowe 1969), 13.4 (Hanneman and Ruhde 1978) and 3.9 (Liu and Douches 1993). Conversely, IvP48 and IvP35 had 255 and 276 DH100F, respectively (Hermsen and Verdenius 1973). Later, Hutten et al. (1993) reported that DH100F values for IvP35, IvP48 and IvP101 were 152, 170 and 255, respectively and, although they lacked replication, they noted a significant interaction of the pistillate parent with the HIs. Nonetheless, IvP101 has been the prevalent HI used to generate dihaploid lines (Manrique-Carpintero et al. 2018; Pham et al. 2019; Yermishin and Voronkova 2017). Our results show that PL4's DH100F value (69) was significantly higher than IvP101 (44) and IvP35 (39) (Table 1).
The Haploid Induction Rate (HIR) seems to be the most adequate trait to compare HIs across different crops. The HIR of PL-4 ( $\sim 11 \%$ dihaploids/well-developed seed) compares favorably to that of elite RWS-derived maize HIs, which displayed values of 8 to $13 \%$ (Chaikam et al. 2016). In wheat, some HIs TaMTL-edited plants reach up to $15.7 \%$ (Liu et al. 2020). In rice, HI Osmatl-edited plants display 2-6\% (Yao et al. 2018). In contrast, in sorghum, HIs yield up to $2 \%$ haploids (Hussain and Franks 2019).

The selection of the spotless seeds during the haploid induction process can be time consuming, thus a reduced amount of Spotted $100 F$ is convenient for fast screening. Our results showed that the Spotted $100 F$ value was significantly lower for PL-4 and IvP101, than for IvP35, which was nearly twofold the PL-4 value (Table 1). We evaluated the ratio of spotted/spotless seeds of the HIs. PL-4 displayed 2.5:1, while IvP101 and IvP35 exhibited 4.1:1 and 5.6:1, respectively. Following Hermsen and Verdenius (1973) classification of high (6:1) versus low (3:1) seed setters, we assigned IvP35 as high- and PL-4 and IvP101 as low-seed setters. Hermsen and Verdenius (1973) also stressed that a high-seed set is an unfavorable trait while a low-seed set can be beneficial when it does not compromise the HIR. Same authors also noted a high correlation $(r=0.93)$ between $S S$ and the haploids generated by low-seed setters. Our findings indicate a significant but low correlation between $S S$ and $D H 100 F$ for the low-seed 
setters: PL-4 and IvP101 $(r=0.34$ and $r=0.49$, respectively, $p<0.05$ ).

Currently, D- and T- type cytoplasm are the most prevalent in modern cultivars and they are related to male sterility. The cytoplasmic diversity of breeding stocks has prompted a call for incorporating different cytoplasmic types in breeding schemes (Hosaka and Sanetomo 2012; Provan et al. 1999; Sanetomo and Gebhardt 2015). We evaluated the performance of the HIs across the cytoplasmic type of pistillate parents. Our results indicate that PL-4 had the most homogeneous behavior across cytoplasm types and the highest mean for the most important efficiency traits-DH100F and HIR (Fig. 3).

Abnormal or lethal phenotypes among the progeny from a haploid induction cross are common, reflecting the genetic load of deleterious or lethal alleles from their tetraploid pistillate parents (Hermsen et al. 1978; Van Breukelen et al. 1977; Hutten et al. 1993; Pham et al. 2019). These compromised plantlets cannot survive further rounds of multiplications and agronomical analysis. For example, Pham et al. (2019) found that $20 \%$ of dihaploids derived from cv. Superior and IvP101 could not be evaluated for agronomic traits under field conditions due to their poor vigor. By comparison, in our screenhouse study less than $10 \%$ of the spotless plants were lost.

We have demonstrated the use of a combination of HIs, cytoplasm type and genetic background to boost haploid induction within a breeding program. The extensive haploid induction crosses performed in this study were aimed at incorporating several traits of interest from the tetraploid pool into a hybrid diploid breeding pipeline.

PL-4 is available at the CIP Genebank and has been deposited in the US potato germplasm repository and therefore available to the potato community to accelerate breeding and particularly the conversion of cultivated potato to diploidy.

\section{Availability}

In vitro plantlets of PL-4 are available and can be requested from CIP Lima, Peru by email at CIP-Germplasm@ cgiar.org. In addition, PL-4 has been deposited in the US Potato Genebank in Sturgeon Bay, Wisconsin (PI695419). If use of PL-4 contributes to development of new variety(s), or scientific discovery(s), it is requested to recognize CIP as the breeder.

Supplementary Information The online version contains supplementary material available at https://doi.org/10.1007/s12230-021-09839-y.

Acknowledgments This research was undertaken and funded as part of the CGIAR Research Program on Roots, Tubers and Bananas (RTB) and the National Science Foundation Plant Genome Integrative Organismal Systems (IOS) Grant 1444612 (Rapid and Targeted Introgression of Traits via Genome Elimination).
We acknowledge the contributions of the late CIP scientists Rolando Cabello and Dr. Mahesh Upadhya, who pioneered haploid induction research at CIP and developed PL-4; Dr. Awais Khan and Elisa Mihovilovich for their assistance in various aspects of the development of this work; Juan Huaccachi, Flor Osorio and Rene Asto provided technical support for the project.

Open Access This article is licensed under a Creative Commons Attribution 4.0 International License, which permits use, sharing, adaptation, distribution and reproduction in any medium or format, as long as you give appropriate credit to the original author(s) and the source, provide a link to the Creative Commons licence, and indicate if changes were made. The images or other third party material in this article are included in the article's Creative Commons licence, unless indicated otherwise in a credit line to the material. If material is not included in the article's Creative Commons licence and your intended use is not permitted by statutory regulation or exceeds the permitted use, you will need to obtain permission directly from the copyright holder. To view a copy of this licence, visit http://creativecommons.org/licenses/by/4.0/.

\section{References}

Amundson, K.R., B. Ordoñez, M. Santayana, E.H. Tan, I.M. Henry, E. Mihovilovich, M. Bonierbale, and L. Comai. 2020. Genomic outcomes of haploid induction crosses in potato (Solanum tuberosum L.). Genetics 214: 369-380.

Amundson, K.R., B. Ordoñez, M. Santayana, M.L. Nganga, I.M. Henry, M. Bonierbale, A. Khan, E.H. Tan, and L. Comai. 2021. Rare instances of haploid inducer DNA in potato dihaploids and ploidydependent genome instability. The Plant Cell. https://doi.org/10. 1093/plcell/koab100.

Bradshaw, J.E. 2007. Breeding potato as a major staple crop. In Breeding major food staples, ed. M.S. Kang and P.M. Priyadarshan, 277-332. Oxford: Blackwell Scientific Publishing.

Brien, C.J. 2020. asremlPlus: Augments Asreml-R in fitting mixed models and packages generally in exploring prediction differences. $\mathrm{R}$ package version 4.1-28. Available online: $\mathrm{https}: / /$ cran.at.r-project. org/package=asremlPlus. Accessed on 15 November 2020 .

Butler, D.G., B.R. Cullis, A.R. Gilmour, B.G. Gogel, and R. Thompson. 2017. ASReml-R reference manual version 4. VSN international ltd, Hemel Hempstead, HP1 1ES, UK.

Chaikam, V., L. Martinez, A.E. Melchinger, W. Schipprack, and P.M. Boddupalli. 2016. Development and validation of red root markerbased haploid inducers in maize. Crop Science 56: 1678-1688.

Clulow, S.A., M.J. Wilkinson, R. Waugh, E. Baird, M.J. Demaine, and W. Powell. 1991. Cytological and molecular observations on Solanum phureja-induced dihaploid potatoes. Theoretical and Applied Genetics 82: 545-551.

Dongyu, Q., Z. Dewei, M.S. Ramanna, and E. Jacobsen. 1995. A comparison of progeny from diallel crosses of diploid potato with regard to the frequencies of 2n-pollen grains. Euphytica 92: 313-320.

Gomez 2006. Guía para las caracterizaciones morfológicas básicas en colecciones de papas nativas. En Manual para caracterización In situ de cultivos nativos, ed. R. Estrada, T. Medina, A. Roldan, 26-50. Instituto Nacional de Investigación y Extensión Agraria-INIEA.

Hanneman, R.E., and R.W. Ruhde. 1978. Haploid extraction in Solanum tuberosum group Andigena. American Potato Journal 55: 259-263.

Hermsen, J.G.Th, and J. Verdenius. 1973. Selection from Solanum tuberosum group phureja of genotypes combining high-frequency haploid induction with homozygosity for embryo-spot. Euphytica 22: $244-259$. 
Hermsen, J.G.T., L.M. Taylor, E.W.M. Van Breukelen, and A. Lipski. 1978. Inheritance of genetic markers from two potato dihaploids and their respective parent cultivars. Euphytica 27: 681-688.

Hosaka, K., and R. Sanetomo. 2012. Development of a rapid identification method for potato cytoplasm and its use for evaluating Japanese collections. Theoretical and Applied Genetics 125: 1237-1251.

Hussain, T., and C. Franks. 2019. Discovery of Sorghum haploid induction system. Methods in Molecular Biology 1931: 49-59.

Hutten, R.C.B., E.J.M.M. Scholberg, D.J. Huigen, J.G.T. Hermsen, and E. Jacobsen. 1993. Analysis of dihaploid induction and production ability and seed parent x pollinator interaction in potato. Euphytica 72: 61-64.

Jansky, S.H., A.O. Charkowski, D.S. Douches, G. Gusmini, C. Richael, P.C. Bethke, D.M. Spooner, R.G. Novy, H. De Jong, W.S. De Jong, and others. 2016. Reinventing potato as a diploid inbred line-based crop. Crop Science 56: 1412-1422.

Lindhout, P., D. Meijer, T. Schotte, R.C.B. Hutten, R.G.F. Visser, and H.J. van Eck. 2011. Towards F1 hybrid seed potato breeding. Potato Research 54: 301-312.

Liu, C.-A., and D.S. Douches. 1993. Production of haploids of potato (Solanum tuberosum subsp. tuberosum) and their identification with electrophoretic analysis. Euphytica 70: 113-126.

Liu, C., Y. Zhong, X. Qi, M. Chen, Z. Liu, C. Chen, X. Tian, J. Li, Y. Jiao, D. Wang, Y. Wang, M. Li, M. Xin, W. Liu, W. Jin, and S. Chen. 2020. Extension of the in vivo haploid induction system from diploid maize to hexaploid wheat. Plant Biotechnology Journal 18: 316-318.

Manrique-Carpintero, N.C., J.J. Coombs, G.M. Pham, F.P.E. Laimbeer, G.T. Braz, J. Jiang, R.E. Veilleux, C.R. Buell, and D.S. Douches. 2018. Genome reduction in tetraploid potato reveals genetic load, haplotype variation, and loci associated with agronomic traits. Frontiers in Plant Science 9: 944. https://doi.org/10.3389/fpls. 2018.00944.

Mihovilovich, E., M. Aponte, H. Lindqvist-Kreuze, and M. Bonierbale. 2013. An RGA-derived SCAR marker linked to PLRV resistance from Solanum tuberosum ssp. andigena. Plant Molecular Biology Reporter 32: 117-128.

Mihovilovich, E., R. Sanetomo, K. Hosaka, B. Ordoñez, M. Aponte, and M. Bonierbale. 2015. Cytoplasmic diversity in potato breeding: Case study from the international potato center. Molecular Breeding 35: 137-146.

Montelongo-Escobedo, H., and P.R. Rowe. 1969. Haploid induction in potato: Cytological basis for the pollinator effect. Euphytica 18: 116-123.

Ordoñez, B., M. Orrillo, and M.W. Bonierbale. 2017. Technical manual potato reproductive and cytological biology. International potato center (CIP). $65 \mathrm{p}$.

Ortiz, R. and E. Mihovilovich. 2020. Genetics and cytogenetics of the potato. In: The potato crop. Its agricultural, nutritional and social contribution to humankind. Ed. H. Campos H., O. Ortiz. Cham (Switzerland). Springer, Cham.

Ortiz, R., E.L. Camadro, and M. Iwanaga. 1993. Utilización potencial de clones de papa obtenidos por autofecundación como inductores de haploidia en cruzamientos 4x x 2x. Revista Latinoamericana de la Papa 5: 46-53.

Peloquin, S.J., A.C. Gabert, and R. Ortiz. 1996. Nature of 'pollinator' effect in potato (Solanum tuberosum L.) haploid production. Annals of Botany 77: 539-542.

Pham, G.M., G.T. Braz, M. Conway, E. Crisovan, J.P. Hamilton, F.P.E. Laimbeer, N. Manrique-Carpintero, L. Newton, D.S. Douches, J. Jiang, R.E. Veilleux, and C.R. Buell. 2019. Genome-wide inference of somatic translocation events during potato dihaploid production. The Plant Genome 12: 180079. https://doi.org/10.3835/ plantgenome2018.10.0079.

Provan, J., W. Powell, H. Dewar, G. Bryan, G.C. Machray, and R. Waugh. 1999. An extreme cytoplasmic bottleneck in the modern European cultivated potato (Solanum tuberosum) is not reflected in decreased levels of nuclear diversity. Proceedings of the Royal Society of London. Series B: Biological Sciences 266: 633-639.

R Core Team. 2020. Core R: A language and environment for statistical computing, version 3.5. 3. Vienna: R Foundation for Statistical Computing.

Rokka, V.-M., L. Pietilä, and E. Pehu. 1996. Enhanced production of dihaploid lines via anther culture of tetraploid potato (Solanum tuberosum L. ssp. tuberosum) clones. American Potato Journal 73: $1-12$.

Sanetomo, R., and C. Gebhardt. 2015. Cytoplasmic genome types of European potatoes and their effects on complex agronomic traits. BMC Plant Biology 15: 162. https://doi.org/10.1186/s12870-0150545-y.

Tan, E.H., I.M. Henry, M. Ravi, K.R. Bradnam, T. Mandakova, M.P. Marimuthu, I. Korf, M.A. Lysak, L. Comai, and S.W. Chan. 2015. Catastrophic chromosomal restructuring during genome elimination in plants. eLife 4: e06516. https://doi.org/10.7554/eLife.06516.

Van Breukelen, E.W.M., M.S. Ramanna, and J.G.Th. Hermsen. 1977. Parthenogenetic monohaploids $(2 \mathrm{n}=\mathrm{x}=12)$ from Solanum tuberosum L. and $S$. verrucosum Schlechtd. and the production of homozygous potato diploids. Euphytica 26: 263-271.

Velásquez, A.C. 2005. Caracterización genética de la resistencia al virus del enrollamiento de la hoja de papa (PLRV) en un cultivo de Solanum tuberosum ssp. andigena asistida por marcadores moleculares. B.Sc. Thesis. Universidad Nacional Agraria La Molina, Lima, Peru.

Wangenheim, K.H.v., S.J. Peloquin, and R.W. Hougas. 1960. Embryological investigations on the formation of haploids in the potato (Solanum tuberosum). Zeitschrift fur Vererbungslehre 91: 391-399.

Yao, L., Y. Zhang, C. Liu, Y. Liu, Y. Wang, D. Liang, J. Liu, G. Sahoo, and T. Kelliher. 2018. OsMATL mutation induces haploid seed formation in indica rice. Nature Plants 4: 530-533.

Yermishin, A.P., and E.V. Voronkova. 2017. Development of initial material for marker assisted potato (Solanum tuberosum L.) parental line breeding at the diploid level. Agricultural and Biological Chemistry. 52: 50-62. 